\title{
Non-tuberculous mycobacterial lung disease due to multiple "minor" risk factors: an illustrative case and a review of these "lesser elements"
}

\author{
Patrick Moon ${ }^{1}$, Elizabeth Guillaumin ${ }^{2}$, Edward D. Chan ${ }^{3,4,5}$ \\ ${ }^{1}$ Naval Medical Center, San Diego, CA, USA; ${ }^{2}$ San Jose, CA, USA; ${ }^{3}$ Department of Academic Affairs, National Jewish Health, Denver, CO, USA; \\ ${ }^{4}$ Division of Pulmonary Sciences and Critical Care Medicine, University of Colorado Anschutz Medical Campus, Aurora, CO, USA; ${ }^{5}$ Rocky \\ Mountain Regional Veterans Affairs Medical Center, Aurora, CO, USA \\ Correspondence to: Edward D. Chan, MD. D509, Neustadt Building, National Jewish Health, 1400 Jackson Street, Denver, CO 80206, USA. \\ Email: ChanE@NJHealth.org.
}

Submitted Feb 22, 2020. Accepted for publication Aug 06, 2020.

doi: $10.21037 /$ jtd-20-986

View this article at: http://dx.doi.org/10.21037/jtd-20-986

\section{Introduction}

Non-tuberculous mycobacterial (NTM) lung disease typically occurs in those with structural lung diseases such as pre-existing bronchiectasis and chronic obstructive pulmonary disease (COPD, typically emphysema). Prototypical causes of bronchiectasis include cystic fibrosis (CF), alpha-1-antitrypsin (AAT) deficiency, primary ciliary dyskinesia (PCD), Sjogren's syndrome, and sequela of prior tuberculosis or other bacterial pneumonia, as well as several other uncommon disorders. However, it is well acknowledged that NTM can also cause lung disease in otherwise healthy subjects. We encountered an individual with mild but bona fide NTM lung disease who appeared to have multiple "minor" risk factors for it. Since these factors are often not discussed in the context of NTM, we have taken this opportunity to review their role in the acquisition of NTM lung disease.

\section{Illustrative case}

A 66-year-old woman is referred for evaluation and management of Mycobacterium avium complex (MAC) lung infection, manifested by a chronic cough and bloodstreaked sputa, the latter occurring 2 months prior to the referral. Eight years before, at age 58 years, a chest CT scan to evaluate a mild chronic productive cough — present for 3 months-revealed mild bronchiectasis and peripheral nodularity in the left upper lobe, but no interventions were made.

Pertinent medical and surgical history include hypothyroidism and uterine sarcoma, the latter treated with a total hysterectomy and bilateral salpingo-oophorectomy and adjunctive cis-platinum and ifosfamide 14 years ago. Gastroesophageal reflux (GER) was also present for many years with the patient preferring to sleep on her left side with no head-of-bed elevation. Family history is notable for father with lung cancer and a maternal grandfather with pulmonary tuberculosis. She is a never smoker and drinks half a glass of wine a day. She has a horse that she visits on a farm with consequent exposures to soil and dust. Medications included levothyroxine, dexlansoprazole, zolpidem, celecoxib, and various over-the-counter vitamins, minerals, and supplements.

On examination, the temperature is $36.9^{\circ} \mathrm{C}$, heart rate 82 per minute, blood pressure $123 / 62 \mathrm{mmHg}$, respiratory rate 18 per minute, $\mathrm{SpO}_{2} 98 \%$ on room air, and body mass index (BMI) of $19 \mathrm{~kg} / \mathrm{m}^{2}$. Physical examination is unremarkable with normal breath sounds.

The complete blood count, electrolytes, renal and hepatic functions, immunoglobulin levels, IgG subclass levels, and antibody responses to diphtheria, tetanus and pneumococcus are within normal limits. The blood $\mathrm{T}$ and B cell subsets, natural killer cell function, and interferon gamma (IFN $\gamma$ ) level are also normal. The cystic fibrosis conductance regulator (CFTR) genotype is heterozygous for delta F508. The AAT protease inhibitor $(\mathrm{Pi})$ phenotype is PiMS and the level is $106 \mathrm{mg} / \mathrm{dL}$ (normal range, 72 to 

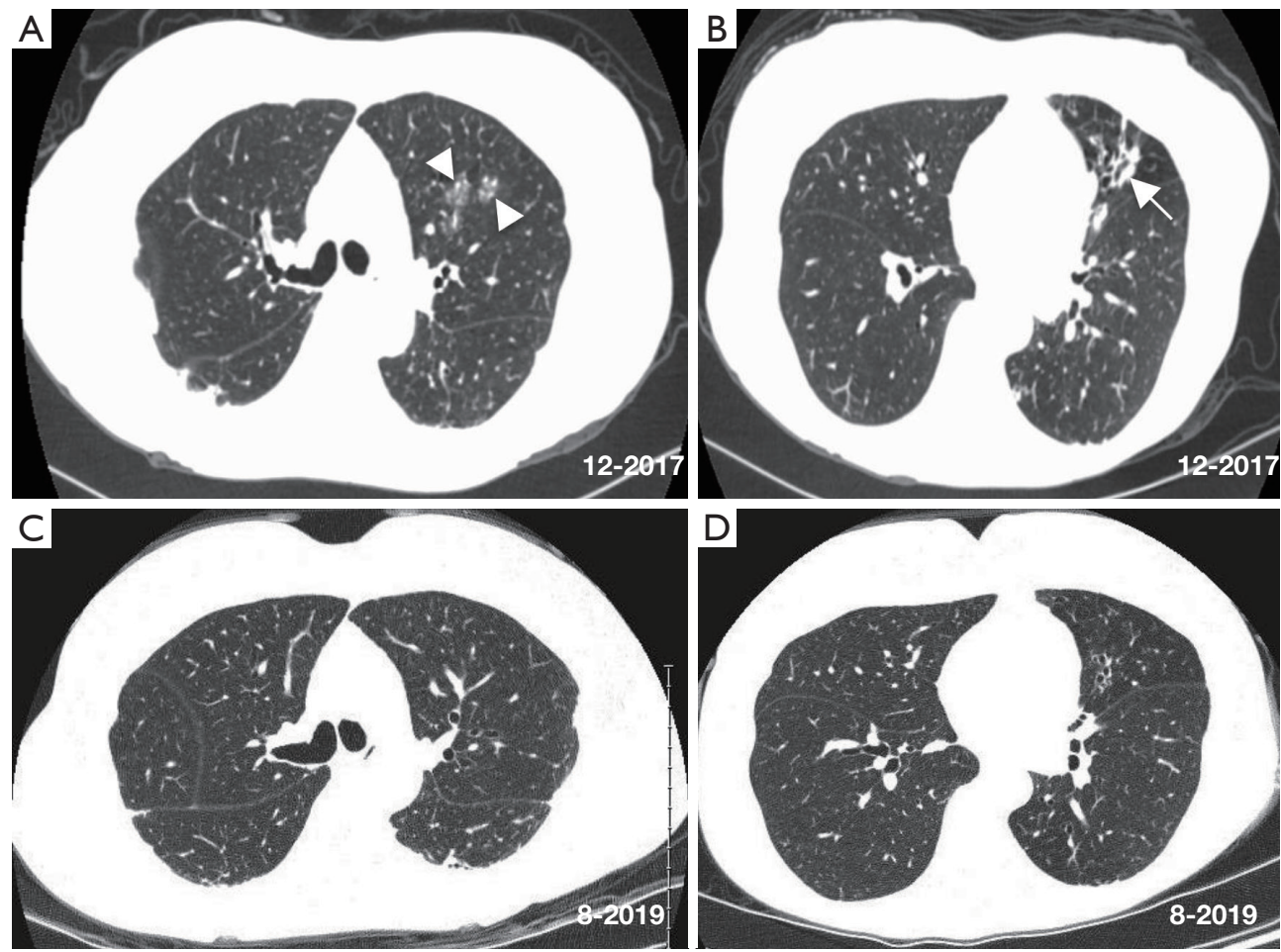

Figure 1 Axial chest CT scan images at the time of referral show relatively mild centrilobular nodules/ground glass opacities (arrowheads) and bronchiectasis (arrow) affecting the left lung more than the right lung (A,B). Chest CT scan nearly 2 years later (C,D) show modest radiographic improvement with resolution of the left upper lobe ground glass opacity, decrease in subpleural densities, and minimal to modest improvement of the lingula following antibiotic treatment for NTM, use of airway clearance measures, implementation of head-ofbed elevation and other anti-reflux measures, and reduction of soil aerosol exposures. CT, computed tomography; NTM, Non-tuberculous mycobacterial.

$192 \mathrm{mg} / \mathrm{dL}$ ). Six sputum cultures within the past 2 months were all positive for $M$. avium, sensitive to clarithromycin, rifampin, rifampin-ethambutol combination, rifabutin, and clofazimine; the minimal inhibitory concentration to amikacin was 8 to $32 \mu \mathrm{g} / \mathrm{mL}$.

A CT scan 2 months before referral and compared to a CT scan 8 years prior revealed increased nodular ground glass opacities and development of bronchiectasis in the left upper lobe, progression of bronchiectasis in the lingula with associated mucus plugging and scarring, bilateral subpleural densities, and nodules in the posterior left lower lobe (Figure 1A,B). Spirometry, lung volumes, and diffusion capacity for carbon monoxide are within normal limits. A tailored barium swallow revealed decreased and delayed hyolaryngeal elevation with delayed epiglottic inversion, and moderately deep, non-transient laryngeal penetration of thin barium. The esophagram is unremarkable.

She was eventually begun on daily azithromycin, rifampin and ethambutol as well as airway clearance and anti-reflux measures that included dietary precautions and head-of-bed elevation using an adjustable bed. After 1 month of treatment, her sputum converted to negative. She was treated for 12 consecutive months with the triple antibiotics with subsequent improvement in chest CT abnormalities (Figure 1C,D).

\section{Discussion}

NTM are ubiquitous in the environment-in soil, water, and biofilms-and thus most individuals are likely exposed to NTM by inhalation, ingestion, and/or aspiration. A study from Germany found that the most abundant NTM in soil and dust was M. avium - the same species found in our patient-present in 33\% of dust samples and $22 \%$ of soil samples but interestingly, no $M$. avium was isolated from water sources or biofilms (1). However, because 
there are regional variations in the NTM species isolated from environmental sources (2), it does not rule out the possibility that our patient acquired the $M$. avium from a water or biofilm source despite her periodic exposures to aerosolized dust and soil. As NTM is so prevalent in the environment, exposures to them are likely widespread; but since NTM lung disease is relatively uncommon, it suggests that those with such a disorder are likely to possess one or more host susceptibility factors.

Isolated NTM lung disease may occur de novo in normal lungs but is more likely to develop in those with pre-existing bronchiectasis or COPD. The three most common genetic disorders associated with bronchiectasis are CF, AAT deficiency, and PCD $(3,4)$. Other disorders known to be associated with bronchiectasis include Williams-Campbell syndrome (cartilage defect), Mounier-Kuhn syndrome (elastin defect resulting in marked airway dilatation), and Sjogren's syndrome (dry, inspissated mucus leading to bronchiectasis) as well as sequelae from suboptimally treated pyogenic bacterial pneumonia or tuberculosis. Other predisposing conditions for NTM lung disease include pulmonary alveolar proteinosis, use of antagonists to tumor necrosis factor-alpha (TNF $\alpha$ ), and aspiration due to swallowing dysfunction or laryngopharyngeal reflux.

While our patient does not have the prototypical major risk factors for NTM lung disease (e.g., CF or COPD), we posit that the presence of several "minor" host risk factors-in addition to environmental exposure to NTMcontaining soil and dust-may have worked in concert to significantly increase her predisposition. Thus, in the context of our patient, we will discuss the possible role that the following may play in the predisposition to NTM lung disease: (I) CFTR heterozygosity, (II) AAT heterozygosity, (III) GER, (IV) low BMI, (V) post-menopausal status, and (VI) exposure to silica/dust (Figure 2).

\section{CFTR anomalies and susceptibility to NTM}

$\mathrm{CF}$ is an autosomal recessive disorder caused by mutation of the CFTR gene. The prevalence of a CFTR gene mutation in the Caucasian population is estimated to be 1 in 20 individuals, resulting in the occurrence of CF in 1 in 2,000-2,500 live births (5). CF patients, even those with milder forms of CFTR mutations (e.g., various compound heterozygosity), are particularly susceptible to recurrent and chronic bacterial infections including those due to Staphylococcus aureus, Pseudomonas aeruginosa, Burkbolderia cepacia complex, fungi, and NTM (6-8). The mechanisms for this susceptibility are likely protean including inspissated mucus with reduced ability to clear bacteria-laden mucus, secondary ciliary dysfunction due to chronic bronchial infection, and reduced human beta-defensin-2 function and level (9). Macrophage dysfunction due to CFTR dysfunction has also been demonstrated and embraces impaired phagocytosis, increased apoptosis, decreased autophagy, impaired clearance of apoptotic neutrophils (i.e., reduced efferocytosis), and excessive production of inflammatory mediators to microbial stimuli (10-12). In simplistic terms, macrophages may be divided into the M1 ("pro-inflammatory") and M2 ("anti-inflammatory") phenotypes. Whether the M1 or the M2 population predominates in the CF lung is controversial but there is evidence that CF macrophages are defective in switching between these two phenotypes (13).

While our patient is only heterozygous for the delta F508 CFTR gene mutation, it is increasingly recognized that individuals who are heterozygous carriers of a single CFTR mutation may also be more susceptible to NTM lung infection, resulting in bronchiectasis $(14,15)$. Whether the one defective CFTR gene increases the susceptibility to NTM, bronchiectasis, or both is not known. Because one study showed that family members not affected with NTM infection have greater frequency of CFTR gene mutation than their relatives with NTM lung disease, it suggests that bronchiectasis in CF patients may be the predisposing factor to NTM infection and not necessarily the CFTR mutation per se although each possibility is not mutually exclusive of the other (16).

\section{AAT anomalies and susceptibility to NTM}

Whether AAT deficiency is associated with bronchiectasis is controversial, although there is increasing evidence of at least an association. In a study of over 200 bronchiectatics, the frequency of abnormal AAT genotypes was not significantly different than those without bronchiectasis (17). In contrast, others found an association between frank AAT deficiency and bronchiectasis (18-21). Guest and Hansell (18) examined the CT scans in 17 patients with proven AAT deficiency and found that seven had bronchial wall thickening and/or dilatation and one had gross cystic bronchiectasis. Similarly, Parr et al. (19) examined 74 patients with the PiZZ phenotype-the most common anomalous AAT that results in frank AAT deficiencyand found that 70 (95\%) had bronchiectatic changes on CT scan involving an average of 3.7 lobes and 20 (27\%) 


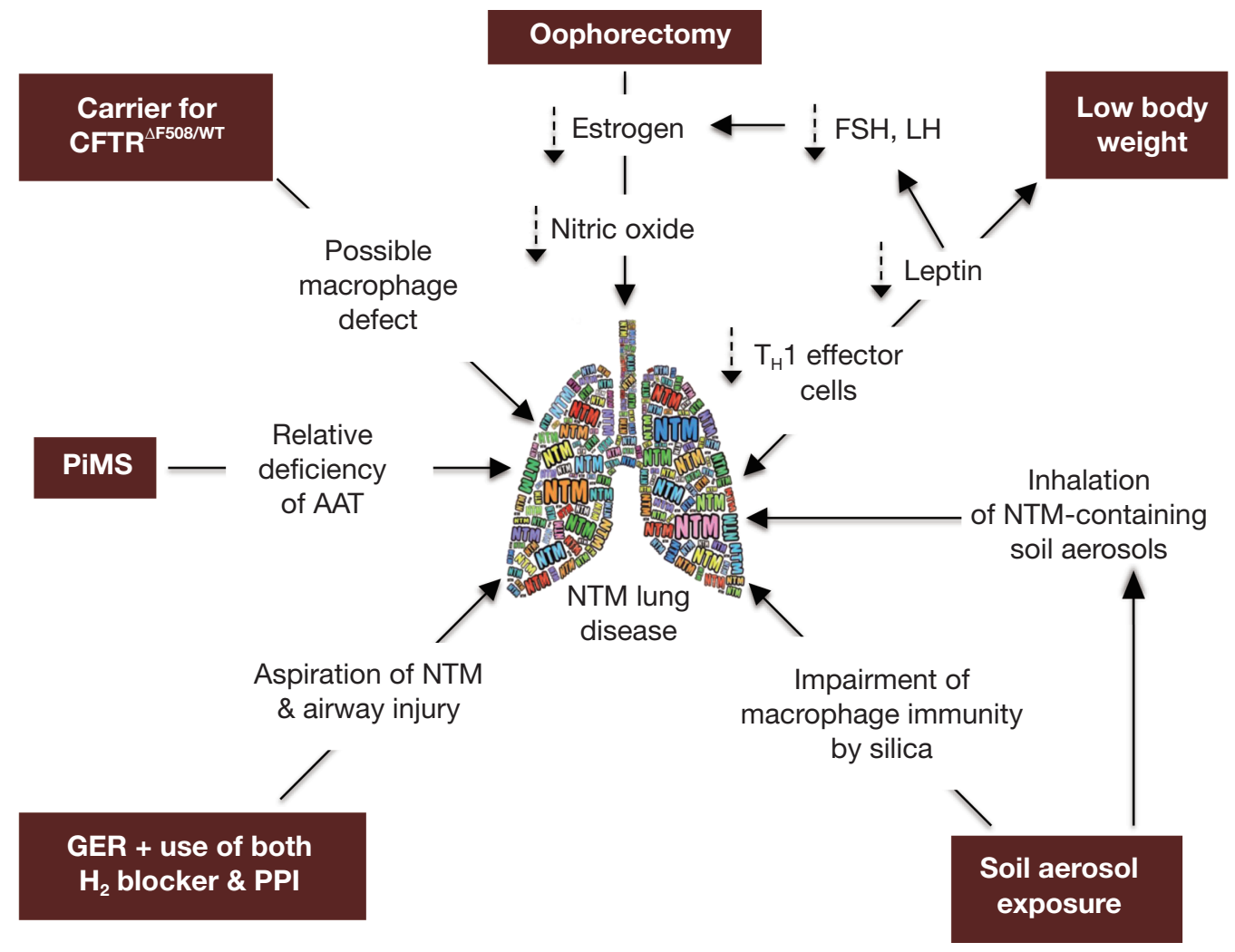

Figure 2 Diagram of the conditions that likely predisposed our subject to NTM lung infection. The texts within the maroon-colored background are the conditions, with the purported mechanisms located "downstream" in the direction of the arrows. The double-ended arrow connecting "NTM lung disease" and "low body weight" is used to denote that low body weight predisposes to NTM lung disease and vice versa. AAT, alpha-1-antitrypsin; FSH, follicle stimulating hormone; GER, gastroesophageal reflux; LH, luteinizing hormone; NTM, non-tuberculous mycobacteria; PiMS, protease inhibitor phenotype "MS"; PPI, proton pump inhibitor.

had "clinically significant bronchiectasis", defined as bronchiectasis affecting $\geq$ four lobes and "regular sputum production". Thus, based on these studies, it is likely that AAT anomalies are uncommon when examining unselected group of bronchiectatics whereas bronchiectasis is commonly seen when analyzing patients with frank AAT deficiency (22). Since the "Z" isoform of AAT may polymerize in the lung and act as a chemoattractant for neutrophils, which are then able to release inflammatory mediators and elastase that incite airway damage, this is a plausible mechanism by which an abnormal AAT protein may predispose to bronchiectasis (23). However, one potential confounder is that COPD itself may be associated with bronchiectasis (24-26).

NTM lung disease has been reported in a patient with frank AAT deficiency with both bronchiectasis and COPD (27). Whether the susceptibility is due to the structural lung disease, AAT deficiency itself, or both is unclear. We and others previously reported that the presence of AAT anomalies-mostly heterozygous PiMS—were more common in patients with NTM lung disease compared to the general U.S. population, suggesting that anomalous AAT may predispose to NTM infection, which can secondarily cause bronchiectasis $(28,29)$. This paradigm is supported by an ex vivo study showing that monocytederived macrophages (MDM) from PiZZ subjects incubated in autologous plasma-both obtained immediately after a session of intravenous AAT augmentation-were better able to control $M$. intracellulare infection than MDM incubated in plasma that were obtained before AAT infusion (30). One mechanism by which AAT augmented macrophage control of $M$. intracellulare was through inhibition of nuclear factor-kappa B (NF-кB), stimulating autophagy (30). Thus, vulnerability of AAT-deficient individuals to NTM lung disease may occur as a result of impaired innate immune function against NTM as well as alterations in lung 
architecture (bronchiectasis and COPD).

Our patient has a PiMS phenotype with a serum AAT that is within normal limits. The $\mathrm{S}$ allele of AAT differs from the normal M-AAT protein by a single amino acid substitution in which glutamic acid on position 264 is substituted by valine but is considered to function normally (31). The mildly reduced serum AAT level associated with $\mathrm{S}$-AAT is due to increased intracellular degradation of newly synthesized S-AAT, decreased secretion from hepatocytes, increased turnover in plasma, and decreased thermal stability of S-AAT; whereas Z-AAT forms polymers and aggregates in the endoplasmic reticulum of the liver, such hepatic accumulation does not occur with the S-AAT protein $(31,32)$. On the surface, it may appear unlikely that the PiMS phenotype of our patient is playing a significant role in susceptibility to NTM since her AAT level was within normal limits and the S-AAT protein is considered to be functional (33). However, since AAT is an acute-phase reactant and its plasma level is known to increase two- to four-fold in inflammatory states, perhaps her AAT level of $106 \mathrm{mg} / \mathrm{dL}$ - which is in the lower half of the normal range-is a relative deficiency; i.e., at a time when her NTM infection was not under control—as evinced by six sputum cultures that were positive-a supranormal AAT level may be the more appropriate response.

\section{GER and susceptibility to NTM}

GER occurs when the normal anti-reflux barrier between the stomach and the esophagus is compromised, such as lower esophageal sphincter incompetence, transient lower esophageal sphincter relaxation, and hiatal hernias. In this regard, severe GER, especially in the supine position as during sleep, is likely the most common cause of aspiration. While it may be difficult to prove definitively whether aspiration is the cause of the bronchiectasis, the prevalence of bronchiectasis in two-thirds of children with chronic pulmonary aspiration strongly indicates that chronic aspiration itself may induce bronchiectasis (34).

There is increasing evidence that aspiration- "from above" due to spillage of oropharyngeal secretions as a result of swallowing dysfunction or "from below" due to GER of contents from the esophagus or stomach-may predispose to NTM lung infection. In three separate studies, GER was present in $26-44 \%$ of pulmonary NTM subjects and $12-28 \%$ in non-NTM infected controls (35-37). However, another study found no difference in GER disease in 184 patients who met criteria for NTM lung disease vs. those who had respiratory NTM isolated but did not meet criteria (38). Those with GER were more likely to be acid-fast smear positive and display more diffuse bronchiolitis and bronchiectasis (35). Use of acid suppression was associated with the presence of consolidation and lung nodules in the setting of NTM lung infection, suggesting greater burden of disease (36). With preferential lateral decubitus position during sleep, aspiration is more likely to occur into the lung that is dependent, as supported by a study demonstrating that the predominant lung affected in asymmetric idiopathic pulmonary fibrosis matched with the preferential (dependent) side to fall asleep in $94 \%$ of the cases (39).

Absence of ingested drink or food, the gastric mucosa normally has a $\mathrm{pH}<2.0$; but with full strength proton pump inhibitor, it increases to $\mathrm{pH}$ of $4-5$ range or even higher $(40,41)$. For slow-growing mycobacteria and $M$. chelonae, the optimal $\mathrm{pH}$ for replication is $\sim 6.0$ whereas for rapidlygrowing mycobacteria, the optimal growth $\mathrm{pH}$ is higher at 7-7.4 (42-44). Thus, acid suppression is likely to enhance the growth of NTM in the stomach. Similarly, mixing of food material with gastric secretions could potentially improve gastric NTM survival by raising the $\mathrm{pH}$ to a midacidic range with subsequent aspiration of viable NTM into the lungs if there is severe GER.

Other than aspiration of NTM into the lungs, could GER of other contents in the stomach predispose to airway injury and subsequent NTM infection? In addition to the acid which can injure airway epithelial cells, aspiration of various gastric and pancreatic enzymes-proteases, lipases, and amylase-has the potential to cause airway mucosal disruption, providing a portal for NTM to initiate and establish residence in the airways. The protease secreted by the stomach is pepsinogen, which is activated by stomach acid to pepsin. The pancreas secretes an array of digestive enzymes including trypsinogen, chymotrypsinogen, and carboxypeptidase, with the first two being converted to their active isozymes in the duodenum in the presence of pancreatic-derived bicarbonate. But perhaps more germane to the pathogenesis of bronchiectasis and impairment of host defense is that the pancreas also secretes several elastases that degrade elastin and other proteins. Besides its key role in the pathogenesis of bronchiectasis, elastase also impairs host immunity against pathogens, by cleaving Fc $\gamma$ receptors and complement receptor 1 from neutrophil surfaces as well as digesting immunoglobulins and complement components from bacterial surfaces (4). These activities impair opsonization of bacteria and reduce recognition of bacteria by neutrophils, leading to decreased 
phagocytosis and killing of pathogens, culminating in exacerbation of bronchiectasis. Thus, if there were pyloric incompetence and esophageal reflux, these pancreatic proteases and elastases may be aspirated, inducing airway damage and host immunosuppression.

Our subject with GER preferred to lie on her left side without use of head-of-bed elevation initially; and, interestingly, her initial abnormal chest $\mathrm{CT}$ and subsequent progression of $M$. avium lung disease were worse in the left lung. Perhaps her lung disease is relatively mild because reflux is less likely to occur with left lateral decubitus than right lateral decubitus (45-47) although this paradigm has been challenged (48). While lying on the left side may be more likely to reduce GER than the right decubitus position, it must be combined with head-of-bed elevation to allow gravitational forces to limit GER in the first place (49).

\section{Low body weight and susceptibility to NTM}

Reduced BMI or subcutaneous fat has been documented in the pulmonary NTM patients and appears to be presently basally and not necessarily caused by the NTM infection itself (50-52). It has been hypothesized that low body weight in itself is a risk factor for NTM lung disease $(50,51,53)$. This concept is supported by very large epidemiological studies (combined $>2.5$ million subjects) showing that thin individuals are much more likely to develop active tuberculosis (54-56). Furthermore, low BMI $\left(<18.5 \mathrm{~kg} / \mathrm{m}^{2}\right)$ has been associated with greater likelihood of both NTM lung disease progression and mortality $(57,58)$. Interestingly, NTM lung disease has been reported in relatively younger women (ages 20-53 years old) with anorexia nervosa (59-64). Since NTM lung disease is much less common in younger individuals than in the elderly, the relatively younger age of those with anorexia nervosa and NTM lung disease would lend credence to the possibility that their thin body habitus is a risk factor. A possible mechanism by which slender individuals with low body fat content may be predisposed to NTM infections is relative deficiency of leptin, an adipokine whose canonical function is that of a satiety hormone (53). However, leptin has a number of immunomodulatory functions that can potentially enhance host-immunity against NTM, including the differentiation of uncommitted $\mathrm{T}_{0}$ cells toward the $\mathrm{T}_{\mathrm{H}} 1 \mathrm{IFN} \gamma$-producing phenotype (65). Indeed, leptin-deficient mice are more susceptible to experimental M. abscessus lung infection (66). Pulmonary NTM patients have been found to have reduced serum leptin levels (67), or a loss in the normal direct relationship between percent body fat and serum leptin concentration (50). Thin, premenopausal women with secondary leptin deficiency may also be more vulnerable to NTM infection because of estrogen deficiency-described below-since another function of leptin is to induce the expression of follicle stimulating hormone (FSH) and luteinizing hormone (LH). Parenthetically, disruption of this leptin-FSH/LH-estrogen axis is why very thin individuals - even if young — are prone to develop hypothalamic amenorrhea.

The occurrence of NTM lung disease in individuals without any known predisposing condition is well recognized; a number of these patients possess Marfanoid features such as life-long slender body habitus and thoracic cage abnormalities such as pectus excavatum and scoliosis (50,51,53,67-71). We and others have postulated that the aforementioned thoracic cage abnormalities may be a marker for an underlying and yet-to-be identified genetic predisposition, perhaps related to a minor variant of Marfan syndrome or ciliary dysfunction (16,50,51,69,70,72-74).

Our patient's BMI reflects her thin body habitus and possibly low body fat. Intuitively, low BMI is more likely to be predictive of low body fat whereas high BMI does not necessarily indicate high body fat as evinced by individuals who may have high BMI with low percentage body fat; e.g., body builders. Nevertheless, in certain groups of individuals, even high BMI may predict increased body fat percentage and obesity (75). According to the National Health and Nutrition Examination Survey (Centers for Disease Control), the average BMI for an adult woman in the U.S. is $26.5 \mathrm{~kg} / \mathrm{m}^{2}$. While our patient's BMI $\left(19 \mathrm{~kg} / \mathrm{m}^{2}\right)$ is within the healthy range of $18.5-24.9 \mathrm{~kg} / \mathrm{m}^{2}$, it is at the lower end and far lower than the average American woman. We reasoned that perhaps the relative deficiency of adipose tissue may have contributed to the susceptibility to NTM in the presence of other "minor" risk factors.

\section{Post-menopausal status and susceptibility to NTM}

Clinical observations accumulated over the past several decades indicate that NTM-associated bronchiectasis without an underlying predisposing condition like CF or PCD is disproportionately more common in postmenopausal women, a demographic group that accounts for $65-85 \%$ of NTM lung disease cases $(28,70,76-80)$, suggesting that estrogen in women (and possibly androgen in men) may play a host-protective role. This notion is supported by reports of MAC infections in those with untreated panhypopituitarism (81). Experimentally, binding 
of estrogen to estrogen receptors on macrophages has been shown to augment both phagocytic function and $\mathrm{Fc} \gamma$ receptor expression (82). This "estrogen-deficiency hypothesis" is corroborated by a study showing that oophorectomized mice were more susceptible to experimental MAC lung infection than mice with intact ovaries (83). Furthermore, reconstitution with exogenous estrogen in the oophorectomized mice reduced the burden of bacilli back to the level seen in the control mice through enhanced production of reactive nitrogen intermediates (83).

Another plausible mechanism by which estrogen protects against NTM is the ability of estradiol to inhibit $\mathrm{NF}-\kappa \mathrm{B}$ activation (84) because we have shown that such inhibition augments autophagy in macrophages, a known killing mechanism against mycobacteria (85). Furthermore, estrogen is known to activate endothelial nitric oxide synthase (eNOS) (86), an enzyme that is also present on airway epithelial cells and that catalyzes the production of nitric oxide (NO), the prototypical reactive nitrogen intermediate. While it is still too early to know whether inhaled NO will be an effective anti-mycobacterial agent, preliminary studies with inhaled NO show promise as adjunctive treatment for NTM lung disease (87-90). Perhaps the lack of estrogen may predispose to NTM due, in part, to decreased NO production. However, other studies do not support a host-protective role for estrogen against mycobacterial infections-as evinced by two studies showing that estrogen receptor-deficient mice infected with $M$. avium have increased production of host-protective $\mathrm{TNF} \alpha$ and IFN $\gamma$, and a trend toward reduced M. avium load in the liver as well as significantly greater control of an ex vivo $M$. avium infection in peritoneal macrophages from estrogen receptor-deficient mice $(91,92)$. Thus, the role estrogen plays in host defense against NTM infections remains to be clarified.

The average age at menopause for the American woman is estimated to be 51 years. The age of onset is due to a number of factors including the BMI, where a higher $\mathrm{BMI}$ is associated with a relative delay in menopause (93). Our patient was menopausal at age 47 years and had hysterectomy and bilateral oophorectomy at age 52 years. Perhaps this earlier period of natural and then surgical menopause predisposed her to NTM lung infection, symptoms of which began when she was 58 years old.

\section{Dust exposure and susceptibility to NTM}

There is convincing evidence that soil is a source of
NTM infections in humans (94-96). In a retrospective cross-sectional study of 1,392 patients with a history of "occupational dust exposure" who had sputum analysis for acid-fast bacilli, NTM were isolated in 82 (97). Multivariate analysis demonstrated that prior tuberculosis, greater number of small opacities, and high-grade of large opacities ( $>10 \mathrm{~mm}$ on longest axis) -with the latter two being potential markers of pneumoconiosis-are significantly associated with NTM culture positivity (97). In a casecontrol study from South Korea to identify risk factors for $M$. kansasii lung disease, 86 such patients were matched with 172 respiratory-healthy controls. Multivariate analysis showed that work in "heavy industries"-occupation considered to have greater dust exposure (e.g., grinding of metals, welding, shipyard work, etc.)—and low BMI were independent risk factors for M. kansasii lung disease (98). Similarly, in Japan, pulmonary MAC disease was more likely to be associated in individuals who live in an area with significantly greater number of primary industries (e.g., agriculture, forestry, and fisheries) or secondary industries (e.g., construction, mining, and processing of materials produced by the primary industries) but not tertiary industries (that provide customer services) (99).

It is well known that silica exposure-even in the absence of radiographic evidence of silicosis-is a strong risk factor for tuberculosis (100). Additionally, silicosis and other forms of pneumoconiosis are also risk factors for NTM lung disease $(101,102)$. Studies of gold miners from South Africa showed that pulmonary silicosis was highly associated with NTM lung disease, with an odds ratio of 12.6 (101). The most common NTM in the South African gold miners was $M$. kansasii, responsible for two-thirds of the cases $(101,102)$. Furthermore, the incidence of $M$. kansasii lung disease was estimated to be 66 per $10^{5}$ person-years in the gold miners (103). Morita and colleagues (104) examined the sputa of 155 subjects with pneumoconiosis and isolated NTM in 60 (39\%) of them. However, only two met criteria for having NTM lung disease as set forth by the American Thoracic Society and Infectious Diseases Society of America $(104,105)$. Nevertheless, this study would support the notion that dust exposure increases infection to NTM and, in the presence of other risk factors, is an initial step in the increased vulnerability to NTM lung disease. $M$. malmoense is an NTM that disproportionately occurs in Northern Europe. Of an unspecified number of patients with coal miner's pneumoconiosis in the United Kingdom, four had sputum positivity for M. malmoense and three of them met 
criteria for NTM lung disease (106). Other case reports have linked NTM lung disease with silicosis or other forms of soil or dust exposures $(94,107)$.

The aforementioned epidemiologic studies are supported experimentally. Gangadharam and co-workers (108) administered silica intravenously to Swiss Webster mouse strain, infected them with $M$. intracellulare, and showed that they had a greater burden of bacilli in the lungs than control mice without silica exposure. Coal and quartz given to guinea pigs by inhalation increased the burden of $M$. kansasii lung disease even though the NTM was given intravenously (109). An often-cited mechanism for silicainduced susceptibility to mycobacterial infections is that following macrophage ingestion of silica particles, these phagocytes are impaired in their effector functions. Two such mechanisms include reducing expression of patternrecognition receptors and inducing premature death of macrophages that have ingested silica particles $(110,111)$.

Our patient owned a horse, which she visited regularly and likely had frequent exposure to aerosolized organic matter and soil that are pervasive in barns and riding corrals, respectively. She did not wear a mask during these visits. Not only are soil and dust exposure a potential source for NTM infection (99,112-116), but, as noted above, inhalation of silica present may potentially compromise host immunity.

\section{Summary}

Our patient with NTM lung disease did not have an identifiable, dominant predisposing condition such as frank CF or COPD. Clinicians should consider the presence of multiple subtle risk factors, perhaps insufficient if acting alone, that predispose to NTM lung disease in those without a prime risk factor.

\section{Acknowledgments}

We thank Dr. Robert Sandhaus of National Jewish Health and Dr. Mark Brantly of the University of Florida College of Medicine for helping discussions on the biochemistry of alpha-1-antitrypsin.

Funding: None.

\section{Footnote}

Conflicts of Interest: All authors have completed the ICMJE uniform disclosure form (available at http://dx.doi. org/10.21037/jtd-20-986). EDC serves as an unpaid editorial board member of Fournal of Thoracic Disease from Dec 2018 to Nov 2020. The other author has no conflicts of interest to declare.

Ethical Statement: The authors are accountable for all aspects of the work in ensuring that questions related to the accuracy or integrity of any part of the work are appropriately investigated and resolved. All procedures performed in studies involving human participants were in accordance with the ethical standards of the institutional and/or national research committee(s) and with the Helsinki Declaration (as revised in 2013).

Open Access Statement: This is an Open Access article distributed in accordance with the Creative Commons Attribution-NonCommercial-NoDerivs 4.0 International License (CC BY-NC-ND 4.0), which permits the noncommercial replication and distribution of the article with the strict proviso that no changes or edits are made and the original work is properly cited (including links to both the formal publication through the relevant DOI and the license). See: https://creativecommons.org/licenses/by-nc-nd/4.0/.

\section{References}

1. Lahiri A, Kneisel J, Kloster I, et al. Abundance of Mycobacterium avium ssp. hominissuis in soil and dust in Germany - implications for the infection route. Lett Appl Microbiol 2014;59:65-70.

2. Lande L. Environmental niches for NTM and their impact on NTM disease. In: Griffith DE, editor. Nontuberculous Mycobacterial Disease: A Comprehensive Approach to Diagnosis and Management. Cham, Switzerland: Springer Nature, 2019:131-44.

3. Chan ED. Vulnerability to nontuberculous mycobacterial lung disease or systemic infection due to genetic/heritable disorders. In: Griffith DE. editor. Nontuberculous Mycobacterial Disease: A Comprehensive Approach to Diagnosis and Management. Switzerland: Springer Nature, 2019:89-110.

4. Solomon GM, Chan ED. Bronchiectasis. In: Broaddus VC, Ernst JD, King TE, et al. editors. Murray \& Nadel's Textbook of Respiratory Medicine. 7th edition. Elsevier Press. 2020.

5. Genetic testing for cystic fibrosis. National Institutes of Health Consensus Development Conference Statement on genetic testing for cystic fibrosis. Arch Intern Med 1999;159:1529-39. 
6. Martiniano SL, Nick JA, Daley CL. Nontuberculous mycobacterial infections in cystic fibrosis. Clin Chest Med 2016;37:83-96.

7. Mojica JE, Richards CJ, Husseini JS, et al. Case 40-2018: A 47-Year-Old Woman with Recurrent Sinusitis, Cough, and Bronchiectasis. N Engl J Med 2018;379:2558-65.

8. Haverkamp MH, van Wengen A, de Visser AW, et al. Pulmonary Mycobacterium abscessus: a canary in the cystic fibrosis coalmine. J Infect 2012;64:609-12.

9. Dalcin D, Ulanova M. The Role of Human BetaDefensin-2 in Pseudomonas aeruginosa Pulmonary Infection in Cystic Fibrosis Patients. Infect Dis Ther 2013;2:159-66.

10. Chen Y, Armstrong DA, Salas LA, et al. Genome-wide DNA methylation profiling shows a distinct epigenetic signature associated with lung macrophages in cystic fibrosis. Clin Epigenetics 2018;10:152.

11. Zhang S, Shrestha CL, Kopp BT. Cystic fibrosis transmembrane conductance regulator (CFTR) modulators have differential effects on cystic fibrosis macrophage function. Sci Rep 2018;8:17066.

12. Assani K, Shrestha CL, Rinehardt H, et al. AR-13 reduces antibiotic-resistant bacterial burden in cystic fibrosis phagocytes and improves cystic fibrosis transmembrane conductance regulator function. J Cyst Fibros 2019;18:622-9.

13. Roesch EA, Nichols DP, Chmiel JF. Inflammation in cystic fibrosis: An update. Pediatr Pulmonol 2018;53:S30-50.

14. Ziedalski TM, Kao PN, Henig NR, et al. Prospective analysis of cystic fibrosis transmembrane regulator mutations in adults with bronchiectasis or pulmonary nontuberculous mycobacterial infection. Chest 2006;130:995-1002.

15. Jarry O, Bertocchi M, Fournel P, et al. Delayed detection of cystic fibrosis in a patient with Mycobacterium avium complex infection. Rev Mal Respir 1994;11:518-21.

16. Szymanski EP, Leung JM, Fowler CJ, et al. Pulmonary nontuberculous mycobacterial infection. A multisystem, multigenic disease. Am J Respir Crit Care Med 2015;192:618-28.

17. Cuvelier A, Muir JF, Hellot MF, et al. Distribution of alpha(1)-antitrysin alleles in patients with bronchiectasis. Chest 2000;117:415-9.

18. Guest PJ, Hansell DM. High resolution computed tomography (HRCT) in emphysema associated alpha-1antitrypsin deficiency. Clin Radiol 1992;45:260-6.

19. Parr DG, Guest PG, Reynolds JH, et al. Prevalence and impact of bronchiectasis in alpha1-antitrypsin deficiency.
Am J Respir Crit Care Med 2007;176:1215-21.

20. Shin MS, Ho KJ. Bronchiectasis in patients with alpha 1-antitrypsin deficiency. A rare occurrence? Chest 1993;104:1384-6.

21. Tomashefski JF, Crystal RG, Wiedemann HP, et al. Alpha 1-Antitrypsin Deficiency Registry Study Group: The bronchopulmonary pathology of alpha-1 antitrypsin (AAT) deficiency: findings of the Death Review Committee of the national registry for individuals with Severe Deficiency of Alpha-1 Antitrypsin. Hum Pathol 2004;35:1452-61.

22. Chan ED, Iseman MD. Significance of bronchiectasis in patients with alpha1-antitrypsin deficiency. Am J Respir Crit Care Med 2008;178:208.

23. Mulgrew AT, Taggart CC, Lawless MW, et al. Z alpha1antitrypsin polymerizes in the lung and acts as a neutrophil chemoattractant. Chest 2004;125:1952-7.

24. Martínez-García MA, de la Rosa Carrillo D, SolerCataluña JJ, et al. Prognostic value of bronchiectasis in patients with moderate-to-severe chronic obstructive pulmonary disease. Am J Respir Crit Care Med 2013;187:823-31.

25. Stockley RA. Bronchiectasis with chronic obstructive pulmonary disease: association or a further phenotype? Am J Respir Crit Care Med 2013;187:786-8.

26. Whitters D, Stockley RA. Bronchiectasis in older patients with chronic obstructive pulmonary disease: prevalence, diagnosis and therapeutic management. Drugs Aging 2013;30:215-25.

27. Hogan PE, Koelsch T, Daley CL, et al. A Woman with a 15-Year History of Bronchiectasis and Recurrent Nontuberculous Mycobacterium Pulmonary Disease. Ann Am Thorac Soc 2018;15:380-2.

28. Chan ED, Kaminska AM, Gill W, et al. Alpha-1antitrypsin (AAT) anomalies are associated with lung disease due to rapidly growing mycobacteria and AAT inhibits Mycobacterium abscessus infection of macophages. Scand J Infect Dis 2007;39:690-6.

29. Kim JS, Tanaka N, Newell JD, et al. Nontuberculous mycobacterial infection: CT scan findings, genotype, and treatment responsiveness. Chest 2005;128:3863-9.

30. Bai X, Bai A, Honda JR, et al. Alpha-1-antitrypsin enhances primary human macrophage immunity against non-tuberculous mycobacteria. Front Immunol 2019;10:1417.

31. Elliott PR, Stein PE, Bilton D, et al. Structural explanation for the deficiency of S alpha 1-antitrypsin. Nat Struct Biol 1996;3:910-1.

32. Curiel DT, Chytil A, Courtney M, et al. Serum alpha 
1-antitrypsin deficiency associated with the common S-type (Glu264----Val) mutation results from intracellular degradation of alpha 1-antitrypsin prior to secretion. J Biol Chem 1989;264:10477-86.

33. de Serres F, Blanco I. Role of alpha-1 antitrypsin in human health and disease. J Intern Med 2014;276:311-35.

34. Piccione JC, McPhail GL, Fenchel MC, et al. Bronchiectasis in chronic pulmonary aspiration: risk factors and clinical implications. Pediatr Pulmonol 2012;47:447-52.

35. Koh WJ, Lee JH, Kwon YS, et al. Prevalence of gastroesophageal reflux disease in patients with nontuberculous mycobacterial lung disease. Chest 2007;131:1825-30.

36. Thomson RM, Armstrong JG, Looke DF. Gastroesophageal reflux disease, acid suppression, and Mycobacterium avium complex pulmonary disease. Chest 2007;131:1166-72.

37. Kang JB, Lee DH, Kwon SH, et al. The Prevalence of Nontuberculous Mycobacterial Lung Disease with or without Reflux Esophagitis. Korean J Gastroenterol 2018;71:18-23.

38. Winthrop KL, McNelley E, Kendall B, et al. Pulmonary nontuberculous mycobacterial disease prevalence and clinical features: an emerging public health disease. Am J Respir Crit Care Med 2010;182:977-82.

39. Tcherakian C, Cottin V, Brillet PY, et al. Progression of idiopathic pulmonary fibrosis: lessons from asymmetrical disease. Thorax 2011;66:226-31.

40. Freedberg DE, Lebwohl B, Abrams JA. The impact of proton pump inhibitors on the human gastrointestinal microbiome. Clin Lab Med 2014;34:771-85.

41. Steingoetter A, Sauter M, Curcic J, et al. Volume, distribution and acidity of gastric secretion on and off proton pump inhibitor treatment: a randomized doubleblind controlled study in patients with gastro-esophageal reflux disease (GERD) and healthy subjects. BMC Gastroenterol 2015;15:111.

42. Piddington DL, Kashkouli A, Buchmeier NA. Growth of Mycobacterium tuberculosis in a defined medium is very restricted by acid $\mathrm{pH}$ and $\mathrm{Mg}(2+)$ levels. Infect Immun 2000;68:4518-22.

43. Portaels F, Pattyn SR. Growth of mycobacteria in relation to the $\mathrm{pH}$ of the medium. Ann Microbiol (Paris) 1982;133:213-21.

44. Forbes BA, Hall GS, Miller MB, et al. Practice Guidelines for Clinical Microbiology Laboratories: Mycobacteria. Clin Microbiol Rev 2018;31:e00038-17.
45. Katz LC, Just R, Castell DO. Body position affects recumbent postprandial reflux. J Clin Gastroenterol 1994;18:280-3.

46. Khoury RM, Camacho-Lobato L, Katz PO, et al. Influence of spontaneous sleep positions on nighttime recumbent reflux in patients with gastroesophageal reflux disease. Am J Gastroenterol 1999;94:2069-73.

47. Person E, Rife C, Freeman J, et al. A Novel Sleep Positioning Device Reduces Gastroesophageal Reflux: A Randomized Controlled Trial. J Clin Gastroenterol 2015;49:655-9.

48. Castillo R, Otero W, Rangel AT. General measures and gastroesophageal reflux disease: Response to Letter to the Editor. Rev Col Gastroenterol 2016;31:174-7.

49. Choi S, Richards JC, Chan ED. Can physics principles help explain why non-tuberculous mycobacterial lung disease is more severe in the right middle lobe and lingula? J Thorac Dis 2019;11:4847-54.

50. Kartalija M, Ovrutsky AR, Bryan CL, et al. Patients with nontuberculous mycobacterial lung disease exhibit unique body and immune phenotypes. Am J Respir Crit Care Med 2013;187:197-205.

51. Kim RD, Greenberg DE, Ehrmantraut ME, et al. Pulmonary nontuberculous mycobacterial disease: prospective study of a distinct preexisting syndrome. Am J Respir Crit Care Med 2008;178:1066-74.

52. Lee SJ, Ryu YJ, Lee JH, et al. The impact of low subcutaneous fat in patients with nontuberculous mycobacterial lung disease. Lung 2014;192:395-401.

53. Chan ED, Iseman MD. Slender, older women appear to be more susceptible to nontuberculous mycobacterial lung disease. Gend Med 2010;7:5-18.

54. Edwards LB, Livesay VT, Acquaviva FA, et al. Height, weight, tuberculous infection, and tuberculous disease. Arch Environ Health 1971;22:106-12.

55. Palmer C, Jablon S, Edwards P. Tuberculosis morbidity of young men in relation to tuberculin sensitivity and body build. Am Rev Tuberc 1957;76:517-39.

56. Tverdal A. Body mass index and incidence of tuberculosis. Eur J Respir Dis 1986;69:355-62.

57. Hayashi M, Takayanagi N, Kanauchi T, et al. Prognostic factors of $634 \mathrm{HIV}$-negative patients with Mycobacterium avium complex lung disease. Am J Respir Crit Care Med 2012;185:575-83.

58. Park J, Cho J, Lee CH, et al. Progression and treatment outcomes of lung disease caused by Mycobacterium abscessus and Mycobacterium massiliense. Clin Infect Dis 2017;64:301-8. 
59. Brown GR. Anorexia nervosa complicated by Mycobacterium xenopi pulmonary infection. J Nerv Ment Dis 1987;175:629-32.

60. Hotta M, Minami Y, Itoda I, et al. A young female patient with anorexia nervosa complicated by Mycobacterium szulgai pulmonary infection. Int $\mathrm{J}$ Eat Disord 2004;35:115-9.

61. Tenholder MF, Pike JD. Effect of anorexia nervosa on pulmonary immunocompetence. South Med J 1991;84:1188-91.

62. Walsh TL, Baca V, Stalling SS, et al. Mycobacterium avium-intracellulare pulmonary infection complicated by cutaneous leukocytoclastic vasculitis in a woman with anorexia nervosa. Infection 2014;42:559-63.

63. Cosson MA, Bertrand JB, Martin C, et al. Temporal interferon-gamma release response to Mycobacterium kansasii infection in an anorexia nervosa patient. J Med Microbiol 2012;61:1617-20.

64. Portillo K, Morera J. Nutritional status and eating disorders: Neglected risk factor for nontuberculous mycobacterial lung disease? Med Hypotheses 2012;78:39-41.

65. Lord GM, Matarese G, Howard JK, et al. Leptin modulates the T-cell immune response and reverses starvation-induced immunosuppression. Nature 1998;394:897-901.

66. Ordway D, Henao-Tamayo M, Smith E, et al. Animal model of Mycobacterium abscessus lung infection. J Leukoc Biol 2008;83:1502-11.

67. Tasaka S, Hasegawa N, Nishimura T, et al. Elevated serum adiponectin level in patients with Mycobacterium aviumintracellulare complex pulmonary disease. Respiration 2010;79:383-7.

68. Guide SV, Holland SM. Host susceptibility factors in mycobacterial infection: Genetics and body morphotype. Infect Dis Clin North Am 2002;16:163-86.

69. Iseman MD. Mycobacterium avium and slender women: an unrequited affair. Trans Am Clin Climatol Assoc 1998;109:199-202; discussion 203-4.

70. Iseman MD, Buschman DL, Ackerson LM. Pectus excavatum and scoliosis. Thoracic anomalies associated with pulmonary disease caused by Mycobacterium avium complex. Am Rev Respir Dis 1991;144:914-6.

71. Holt MR, Kasperbauer SH, Koelsch TL, et al. Similar characteristics of nontuberculous mycobacterial lung disease in men and women. Eur Respir J 2019;54:1900252.

72. Daniels ML, Birchard KR, Lowe JR, et al. Enlarged dural sac in idiopathic bronchiectasis implicates heritable connective tissue gene variants. Ann Am Thorac Soc 2016;13:1712-20.

73. Fowler CJ, Olivier KN, Leung JM, et al. Abnormal nasal nitric oxide production, ciliary beat frequency, and Tolllike receptor response in pulmonary nontuberculous mycobacterial disease epithelium. Am J Respir Crit Care Med 2013;187:1374-81.

74. Talbert J, Chan ED. The association between body shape and nontuberculous mycobacterial lung disease. Expert Rev Respir Med 2013;7:201-4.

75. Ranasinghe C, Gamage P, Katulanda P, et al. Relationship between Body Mass Index (BMI) and body fat percentage, estimated by bioelectrical impedance, in a group of Sri Lankan adults: a cross sectional study. BMC Public Health 2013;13:797.

76. Daley CL, Griffith DE. Pulmonary disease caused by rapidly growing mycobacteria. Clin Chest Med 2002;23:623-32.

77. Field SK, Cowie RL. Lung disease due to the more common nontuberculous mycobacteria. Chest 2006;129:1653-72.

78. Griffith DE, Girard WM, Wallace RJ. Clinical features of pulmonary disease caused by rapidly growing mycobacteria: An analysis of 154 patients. Am Rev Respir Dis 1993;147:1271-8.

79. Okumura M, Iwai K, Ogata H, et al. Clinical factors on cavitary and nodular bronchiectatic types in pulmonary Mycobacterium avium complex disease. Intern Med 2008;47:1465-72.

80. Prince DS, Peterson DD, Steiner RM, et al. Infection with Mycobacterium avium complex in patients without predisposing conditions. N Engl J Med 1989;321:863-8.

81. Koh W-J, Kwon OJ. Mycobacterium avium complex lung disease and panhypopituitarism. Mayo Clin Proc 2005;80:961-2.

82. Chalermskulrat W, Gilbey JG, Donohue JF. Nontuberculous mycobacteria in women, young and old. Clin Chest Med 2002;23:675-86.

83. Tsuyuguchi K, Suzuki K, Matsumoto H, et al. Effect of oestrogen on Mycobacterium avium complex pulmonary infection in mice. Clin Exp Immunol 2001;123:428-34.

84. Deshpande R, Khalili H, Pergolizzi RG, et al. Estradiol down-regulates LPS-induced cytokine production and NFkB activation in murine macrophages. Am J Reprod Immunol 1997;38:46-54.

85. Bai X, Feldman NE, Chmura K, et al. Inhibition of nuclear factor-kappa B activation decreases survival of Mycobacterium tuberculosis in human macrophages. 
PLoS One 2013;8:e61925.

86. Chambliss KL, Shaul PW. Estrogen modulation of endothelial nitric oxide synthase. Endocr Rev 2002;23:665-86.

87. Yaacoby-Bianu K, Gur M, Toukan Y, et al. Compassionate Nitric Oxide Adjuvant Treatment of Persistent Mycobacterium Infection in Cystic Fibrosis Patients. Pediatr Infect Dis J 2018;37:336-8.

88. Bentur L, Masarweh K, Livnat-Levanon G, et al. Nitric oxide inhalations in CF patients infected with Mycobacterium abscessus complex: A prospective, openlabeled, multi-center pilot study. Am J Respir Crit Care Med 2020;201:A5919.

89. Bogdanovski K, Ghaffari A, da Silva JL, et al. Highdose inhaled nitric oxide as a potential therapy against Mycobacterium abscessus lung infection in cystic fibrosis. Pediatr Pulmonol 2018;53:99.

90. Miller CC, McMullin B, Martins J, et al. Inhaled gaseous nitric oxide as a treatment for nontuberculous mycobacteria lung infection study. Pediatr Pulmonol 2018;53:88.

91. Curran EM, Judy BM, Newton LG, et al. Dietary soy phytoestrogens and ERalpha signalling modulate interferon gamma production in response to bacterial infection. Clin Exp Immunol 2004;135:219-25.

92. Lambert KC, Curran EM, Judy BM, et al. Estrogen receptor-a deficiency promotes increased TNF-a secretion and bacterial killing by murine macrophages in response to microbial stimuli in vitro. J Leukoc Biol 2004;75:1166-72.

93. Ceylan B, Ozerdogan N. Factors affecting age of onset of menopause and determination of quality of life at menopause. Turk J Obstet Gynecol 2015;12:43-9.

94. Degroote MA, Pace NR, Fulton K, et al. Relationships between Mycobacterium isolates from patients with pulmonary mycobacterial infection and potting soils. Appl Environ Microbiol 2006;72:7602-6.

95. Fujita K, Ito Y, Hirai T, et al. Genetic relatedness of Mycobacterium avium-intracellulare complex isolates from patients with pulmonary MAC disease and their residential soils. Clin Microbiol Infect 2013;19:537-41.

96. Reed C, von Reyn C F, Chamblee S, et al. Environmental risk factors for infection with Mycobacterium avium complex. Am J Epidemiol 2006;164:32-40.

97. Lee JW, Myong JP. Association between Occupational and Radiological Factors and Nontuberculous Mycobacteria Lung Infection in Workers with Prior Dust Exposure. Int J Environ Res Public Health 2019;16:1966.

98. Kim JH, Seo KW, Shin Y, et al. Risk factors for developing
Mycobacterium kansasii lung disease: A case-control study in Korea. Medicine (Baltimore) 2019;98:e14281.

99. Hamada S, Ito Y, Hirai T, et al. Impact of industrial structure and soil exposure on the regional variations in pulmonary nontuberculous mycobacterial disease prevalence. In J Mycobacteriol 2016;5:170-6.

100. Barboza CE, Winter DH, Seiscento M, et al. Tuberculosis and silicosis: epidemiology, diagnosis and chemoprophylaxis. J Bras Pneumol 2008;34:959-66.

101.Sonnenberg P, Murray J, Glynn JR, et al. Risk factors for pulmonary disease due to culture-positive M. tuberculosis or non-tuberculous mycobacteria in South African gold miners. Eur Respir J 2000;15:291-6.

102. Corbett EL, Churchyard GJ, Clayton T, et al. Risk factors for pulmonary mycobacterial disease in South African gold miners. A case-control study. Am J Respir Crit Care Med 1999;159:94-9.

103. Corbett EL, Hay M, Churchyard GJ, et al. Mycobacterium kansasii and M. scrofulaceum isolates from HIV-negative South African gold miners: incidence, clinical significance and radiology. Int J Tuberc Lung Dis 1999;3:501-7.

104. Morita H, Usami I, Torii M, et al. Isolation of nontuberculous mycobacteria from patients with pneumoconiosis. J Infect Chemother 2005;11:89-92.

105. Griffith DE, Aksamit T, Brown-Elliott BA, et al. An official ATS/IDSA statement: diagnosis, treatment, and prevention of nontuberculous mycobacterial diseases. Am J Respir Crit Care Med 2007;175:367-416.

106.McGrath EE, Bardsley P. An association between Mycobacterium malmoense and coal workers' pneumoconiosis. Lung 2009;187:51-4.

107. de Oliveira Abrão C, de Araújo Filho JA. Mycobacterium sherrisii Lung Infection in a Brazilian Patient with Silicosis and a History of Pulmonary Tuberculosis. Case Rep Infect Dis 2015;2015:498608.

108. Gangadharam PR, Pratt PF, Davidson PT. Experimental infections with Mycobacterium intracellulare. Rev Infect Dis 1981;3:973-8.

109. Policard A, Gernez-Rieux C, Tacquet A, et al. Influence of pulmonary dust load on the development of experimental infection by Mycobacterium kansasii. Nature 1967;216:177-8.

110. Gilberti RM, Joshi GN, Knecht DA. The phagocytosis of crystalline silica particles by macrophages. Am J Respir Cell Mol Biol 2008;39:619-27.

111. Beamer GL, Seaver BP, Jessop F, et al. Acute exposure to crystalline silica reduces macrophage activation in response to bacterial lipoproteins. Front Immunol 2016;7:49. 
112.Jeon D. Infection source and epidemiology of nontuberculous mycobacterial lung disease. Tuberc Respir Dis (Seoul) 2019;82:94-101.

113. Halstrom S, Price P, Thomson R. Review: Environmental mycobacteria as a cause of human infection. Int $\mathrm{J}$ Mycobacteriol 2015;4:81-91.

114.Ichiyama S, Shimokata K, Tsukamura M. The isolation of Mycobacterium avium complex from soil, water, and dusts. Microbiol Immunol 1988;32:733-9.

Cite this article as: Moon P, Guillaumin E, Chan ED. Nontuberculous mycobacterial lung disease due to multiple "minor" risk factors: an illustrative case and a review of these "lesser elements". J Thorac Dis 2020;12(9):4960-4972. doi: 10.21037/ jtd-20-986
115. Nishiuchi Y, Iwamoto T, Maruyama F. Infection sources of a common non-tuberculous mycobacterial pathogen, Mycobacterium avium complex. Front Med (Lausanne) 2017;4:27.

116. Honda JR, Virdi R, Chan ED. Global environmental nontuberculous mycobacteria and their contemporaneous man-made and natural niches. Front Microbiol 2018;9:2029. 